\title{
IDENTIFYING FREQUENCY AND ASSOCIATED FACTORS WITH RESPIRATORY ILLNESSES IN CHILDREN WITH CEREBRAL PALSY.
}

1. MBBS, MCPS, FCPS

Professor\& Head of Paediatrics

Bolan Medical College Quetta.

2. MBBS, M.Phil

Demonstrator Biochemistry

Bolan Medical College Quetta.

3. MBBS

Lady Medical Officer (Paeds) Civil Provincial Hospital Quetta.

4. MBBS, M.Phil

Asst. Prof. Pathology (Hematology)

Bolan Medical College Quetta.

Correspondence Address:

Dr. Shazia Bano

Home Add. H. No. 564 , St. No. 12

Railway Housing Society Near SBK

University,

Brewery Road, Quetta.

drshazia2000@yahoo.com

Article received on:

05/08/2019

Accepted for publication:

04/11/2019

\begin{abstract}
Dilshad Qureshi ${ }^{1}$, Shazia Bano ${ }^{2}$, Hira Idrees ${ }^{3}$, Saima Iram ${ }^{4}$
\end{abstract}
ABSTRACT... Objectives: To identify the frequency and associated factors with respiratory illnesses in children with cerebral palsy. Study Design: Cross-sectional study. Setting: Department of Paediatrics, Unit I. Sandeman Provincial Hospital, Quetta. Period: $8^{\text {th }}$ May 2018 to $7^{\text {th }}$ May, 2019. Material \& Methods: was to determine frequency of hospital admissions due to respiratory illnesses and factors leading to respiratory illnesses in children with cerebral palsy. The study considered 207 patients who were suffering with cerebral palsy. Weight and height/length were taken. Chest was inspected for in drawing of ribs and respiratory rate was counted for a minute. CP child further investigated for having drooling of saliva, chewing difficulties, impaired speech, seizures, GERD, mode of food intake, scoliosis and malnutrition. Descriptive statistics were calculated. Stratification was done and post stratification Chi square test was applied considering p-value $\leq 0.05$ as significant. Conclusion: Among total patients admitted, respiratory illness was observed in $16.4 \%$ patients. It was observed that problem to eat by mouth, oromotor dysfunction and Malnutrition were mostly observed leading factors. Multidisciplinary approach should always be provided to CP children at hospital as well as community level along with parent education related to disease problem. These factors need to be addressed thoroughly. Preventive measurements and treatments should be individualized for each leading factors.

Key words: $\quad$ Admissions, Children, Cerebral Palsy, Factors, Respiratory Illnesses.

Article Citation: Qureshi D, Bano S, Idrees H, Iram S. Identifying frequency and associated factors with respiratory illnesses in children with cerebral palsy. Professional Med J 2020; 27(6):1187-1193. DOI: 10.29309/TPMJ/2020.27.06.4010

\section{Introduction}

Cerebral Palsy (CP) is the commonest and lifelong physical disability among children. ${ }^{1}$ Prevalence of cerebral palsy is around 1.5 to more than 4 per 1000 live births. ${ }^{2}$ It is permanent movement and posture disorders, attributed to non progressive disturbances in the fetal life and developing infant's brain. ${ }^{3}$ Although cerebral palsy is considered as a static encephalopathy, however, few physical, neurological and psychological manifestations can change or progress over time. Many comorbid conditions including epilepsy, severe motor impairments, respiratory and feeding problems, affect life quality and expectancy of $\mathrm{CP}$ child. ${ }^{4}$

Among CP children, respiratory diseases are frequent and leading cause of hospitalization and premature deaths. ${ }^{5,6}$ Blackmore et al, Meehan E et al, and Young NL et al ${ }^{5-7}$ reported number of hospital admissions in CP population due to respiratory illnesses. Previous study has also reported that $\mathrm{CP}$ children have increased incidence of respiratory problems and noisy breathing which may be referred to as usually most common symptom. ${ }^{4}$ Therefore, it may be hypothesized that children with cerebral palsy and other neuro-disabilities have higher frequency of respiratory illnesses than general population.

Many factors are associated with respiratory problems, including oromotor dysfunction ${ }^{5,8}$, respiratory muscle weaknesses, low-upper to lower chest diameter ratio ${ }^{9}$, mode of food intake, scoliosis, malnutrition, seizures and gross motor function level. Blackmore et al and A. Benfera observed strong association of CP child with oromotor dysfunction, when admitted with respiratory problems. ${ }^{5}$ Similarly Blackmore et al reported strong association of GERD scoliosis, 
seizures, malnourished and mode of food intake with respiratory problem. ${ }^{5}$

Based on these findings, empirical antibiotics treatment is becoming an acceptable part of their management without even knowing the distinctive underlying cause or contributing factors.

There is scarcity of detailed comprehensive literature on frequency of respiratory diseases, their causes, potential leading factors and complications. To find out the reason for higher frequency of respiratory illness in children with cerebral palsy, there is dire need to investigate the association of several other contributing factors as well.

Therefore, this study aims to determine frequency of respiratory problems in CP. Furthermore, the analysis of data may help to craft new interventions and strategies to early identify manage and monitor factors leading to respiratory illnesses. Study aim is to also emphasize on need for individualizing treatment and long term follow up for each leading factors.

Advantages of early recognition of leading factors for efficient prevention, management and monitoring processes shall ultimately contribute to improve quality and expectancy of life and thus shall reduce parental stress and burden on health services. To the best of our knowledge no such study in paediatric medicine has been done in this region of Pakistan.

\section{MATERIAL \& METHODS}

This study was conducted from $8^{\text {th }}$ May 2018 to $7^{\text {th } M a y, ~} 2019$ at Department of Paediatrics, Unit I. Sandeman Provincial Hospital, Quetta. Nonprobability consecutive sampling was used for this descriptive cross-sectional study. The sample size of this study is given in the table below.

\begin{tabular}{|c|c|c|c|}
\hline $\begin{array}{c}\text { Sample } \\
\text { Size }\end{array}$ & $\begin{array}{c}\text { Confidence } \\
\text { Level }\end{array}$ & $\begin{array}{c}\text { Anticipated } \\
\text { population } \\
\text { proportion }\end{array}$ & $\begin{array}{c}\text { Absolute } \\
\text { Precision }\end{array}$ \\
\hline 207 & $95 \%$ & $5.1 \%$ & $3 \%$ \\
\hline & Table-I. Sample size & \\
\hline
\end{tabular}

Inclusion Criteria

- All indoor diagnosed cases of cerebral palsy.

- Children age 2-14 years.

- CP child of either sex.

\section{Exclusion Criteria}

- Children with history of genetic, metabolic, psychiatric or neurological disease like spinal muscular dystrophies, Gullien Bar Syndrome, Duchenne Muscular Dystrophy, leucodystrophies, attention deficit hyperactivity disorder and autisim.

Prior to conduct of study, approval by the Research department of CPSP and the research and ethics committee of Sandeman Provincial Hospital Quetta was taken. Children with cerebral palsy fulfilled inclusion criteria were included in study. Procedure, risks and benefits were explained to parents and informed written consent was taken by parents/guardian of patients. Brief history regarding age at diagnosis of $\mathrm{CP}$, residence, parent's educational status and monthly income were taken. Weight in kilograms and height/length were taken in centimeters using weight machine and measuring tape available in ward. Chest was inspected for indrawing of ribs and respiratory rate was counted for a minute. Noisy breathing during inspiration or expiration, findings on auscultation of chest and X-ray chest were noted. CP child fulfilled criteria of having respiratory illness was further investigated for having drooling of saliva, chewing difficulties, impaired speech, seizures, GERD, mode of food intake, scoliosis, all information gathered were recorded. Patient's comfort was prior concern during examination.

Data were entered and analyzed through Statistical Package for Social Sciences (SPSS V-21). Mean and standard deviations were computed for age, weight and height/length. Frequencies and percentage were computed for the qualitative variables i.e. gender, respiratory illnesses, family monthly income, parent's education, residence and leading factors. Effect modifier like, age, weight, gender, parent's education, family monthly income, area of residence were controlled by stratification. Post-stratification Chi 
square test was applied and $p$ value $\leq 0.05$ was taken as significant.

\section{RESULTS}

Total 207 patients of diagnosed cases of cerebral palsy with age 2-14 years meeting inclusion criteria of study were evaluated to determine the hospital admissions due to respiratory illnesses and factors leading to respiratory illnesses. Descriptive statistics were calculated using SPSS version 21. Stratification was done and post stratification Chi square test was applied to observe the effect of modifiers on outcomes. $P$ value $\leq 0.05$ was considered as significant. Out of 207 patients, $58.6 \%$ were male and $41.4 \%$ were female as shown in Table-II.

The distribution of age in terms of frequency and percentages is presented in Table-III. As far as residence is concerned it was observed that $80.9 \%$ patients were belonged to urban areas and remaining $19.1 \%$ patients were belonged to rural areas. The results are presented in Table-IV.

The education of mother and father was evaluated separately. The results showed that $52.6 \%$ mother were illiterate, $36.2 \%$ got education till matric, and $11.2 \%$ got education till graduation or above. The results also showed that among fathers, $26.3 \%$ were illiterate, $56.6 \%$ got education till matric, and $17.1 \%$ got education till graduation or above. The detailed results are presented in Table- $V$ and Table-VI respectively.

The results about family monthly income showed that $55.3 \%$ patients had family income $<15,000$ per month. 38.2\% patient had monthly income $15,000-30,000$. Only $6.6 \%$ patients had monthly income more than 30,000 . The results are presented in Table-VII.

The final outcome i.e. respiratory illness was observed and the results showed that $16.4 \%$ patients had respiratory illness among admitted patients. The results represented in Table-I. As far as factors are concerned, it was observed that oromotor dysfunction was found in 39. $8 \%$ patients, problem of eat food by mouth was observed in $57.7 \%$ patients, GERD was observed in $10.7 \%$ patients, malnutrition was observed in $47.0 \%$ patients, scoliosis was observed in $8.6 \%$ patients and seizure was observed in $19.4 \%$ patients. The frequency of risk factors according to respiratory illness was also evaluated and presented in Table-VIII.

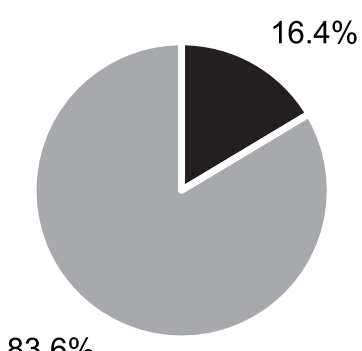

\section{YES $\square$ NO}

Stratification with respect to gender, age, residence, education of mother, education of father, and monthly income was done to observe effect of these modifiers on respiratory illness by using Chi square test. P-value $\leq 0.05$ was considered as significant.

The results showed significant association of respiratory illness with age $(P=0.009)$. But gender, residence, mother education, father education, and monthly income were not significantly associated with respiratory illness.

\begin{tabular}{|c|c|c|c|c|c|c|}
\hline \multirow{3}{*}{ Gender } & \multicolumn{5}{|c|}{ Respiratory IIIness } & \multirow{3}{*}{ P-Value } \\
\hline & \multicolumn{2}{|c|}{ Yes $(n=34)$} & \multicolumn{2}{|c|}{ No $(n=173)$} & \multirow{2}{*}{ Total } & \\
\hline & $\mathbf{N}$ & $\%$ & $\mathbf{N}$ & $\%$ & & \\
\hline Male & 19 & 15.7 & 102 & 84.3 & 121 & \multirow{3}{*}{$0.777^{* *}$} \\
\hline Female & 15 & 17.4 & 71 & 82.6 & 86 & \\
\hline Total & \multicolumn{2}{|c|}{34} & \multicolumn{2}{|c|}{173} & 207 & \\
\hline
\end{tabular}




\begin{tabular}{|c|c|c|c|c|c|c|}
\hline \multirow{3}{*}{ Age } & \multicolumn{5}{|c|}{ Respiratory IIIness } & \multirow{3}{*}{ P-Value } \\
\hline & \multicolumn{2}{|c|}{ Yes $(n=34)$} & \multicolumn{2}{|c|}{ No $(n=173)$} & \multirow{2}{*}{ Total } & \\
\hline & $\mathbf{N}$ & $\%$ & $\mathbf{N}$ & $\%$ & & \\
\hline$>7$ years & 8 & 8.2 & 91 & 91.8 & 99 & \multirow[t]{2}{*}{$0.009 *$} \\
\hline Total & \multicolumn{2}{|c|}{34} & \multicolumn{2}{|c|}{173} & 207 & \\
\hline
\end{tabular}

Table-III. Frequency of respiratory illness according to age

Chi Square Test was applied. P-value $\leq 0.05$ considered as significant. * Significant at 0.05 level.

\begin{tabular}{|c|c|c|c|c|c|c|}
\hline \multirow{3}{*}{ Residence } & \multicolumn{5}{|c|}{ Respiratory IIIness } & \multirow{3}{*}{ P-Value } \\
\hline & \multicolumn{2}{|c|}{ YES $(n=34)$} & \multicolumn{2}{|c|}{ NO $(n=207)$} & \multirow{2}{*}{ Total } & \\
\hline & $\mathbf{N}$ & $\%$ & $\mathbf{N}$ & $\%$ & & \\
\hline Rural & 4 & 10.3 & 35 & 89.7 & 39 & \multirow[t]{2}{*}{$0.413^{\star \star}$} \\
\hline Total & \multicolumn{2}{|c|}{34} & \multicolumn{2}{|c|}{173} & 207 & \\
\hline
\end{tabular}

Table-IV. Frequency of respiratory illness according to area

Chi Square Test was applied. P-value $\leq 0.05$ considered as significant. ** Not Significant at 0.05 level.

\begin{tabular}{|c|c|c|c|c|c|c|}
\hline \multirow{3}{*}{ Mother's Education } & \multicolumn{5}{|c|}{ Respiratory IIIness } & \multirow{3}{*}{ P-Value } \\
\hline & \multicolumn{2}{|c|}{ Yes (n-34) } & \multicolumn{2}{|c|}{ No $(n=173)$} & \multirow{2}{*}{ Total } & \\
\hline & $\mathbf{N}$ & $\%$ & $\mathbf{N}$ & $\%$ & & \\
\hline Matric & 12 & 16.3 & 63 & 83.7 & 75 & \multirow{2}{*}{$0.951 * *$} \\
\hline Graduation or Above & 3 & 11.8 & 20 & 88.2 & 23 & \\
\hline
\end{tabular}

Table-V. Frequency of respiratory illness according to mother's education

Chi Square Test was applied. P-value $\leq 0.05$ considered as significant. $\quad$ ** Not Significant at 0.05 level.

\begin{tabular}{|c|c|c|c|c|c|c|}
\hline \multirow{3}{*}{ Father's Education } & \multicolumn{5}{|c|}{ Respiratory IIIness } & \multirow{3}{*}{ P-Value } \\
\hline & \multicolumn{2}{|c|}{ Yes (n-34) } & \multicolumn{2}{|c|}{ No $(n=173)$} & \multirow{2}{*}{ Total } & \\
\hline & $\mathbf{N}$ & $\%$ & $\mathbf{N}$ & $\%$ & & \\
\hline Matric & 23 & 19.7 & 94 & 80.3 & 117 & \multirow{2}{*}{$0.545^{\star *}$} \\
\hline Graduation or Above & 4 & 11.5 & 31 & 88.5 & 35 & \\
\hline
\end{tabular}

Table-VI. Frequency of respiratory illness according to father's education

Chi Square Test was applied. P-value $\leq 0.05$ considered as significant. $\quad \star \star$ Not Significant at 0.05 level.

\begin{tabular}{|c|c|c|c|c|c|c|}
\hline \multirow{3}{*}{$\begin{array}{l}\text { Family Monthly } \\
\text { Income }\end{array}$} & \multicolumn{5}{|c|}{ Respiratory IIIness } & \multirow{3}{*}{ P-Value } \\
\hline & \multicolumn{2}{|c|}{ Yes $(n=34)$} & \multicolumn{2}{|c|}{ No $(n=173)$} & \multirow{2}{*}{ Total } & \\
\hline & $\mathbf{N}$ & $\%$ & $\mathbf{N}$ & $\%$ & & \\
\hline$<15,000$ & 22 & 19.0 & 93 & 81.0 & 114 & \multirow{4}{*}{$0.682^{\star *}$} \\
\hline $15,000-30,000$ & 11 & 13.8 & 68 & 86.2 & 79 & \\
\hline$>30,000$ & 1 & 10.0 & 12 & 90.0 & 14 & \\
\hline Total & \multicolumn{2}{|c|}{34} & \multicolumn{2}{|c|}{173} & 207 & \\
\hline
\end{tabular}

Table-VII. Frequency of respiratory illness according to monthly income

Chi Square Test was applied. P-value $\leq 0.05$ considered as significant. $\quad$ ** Not Significant at 0.05 level. 


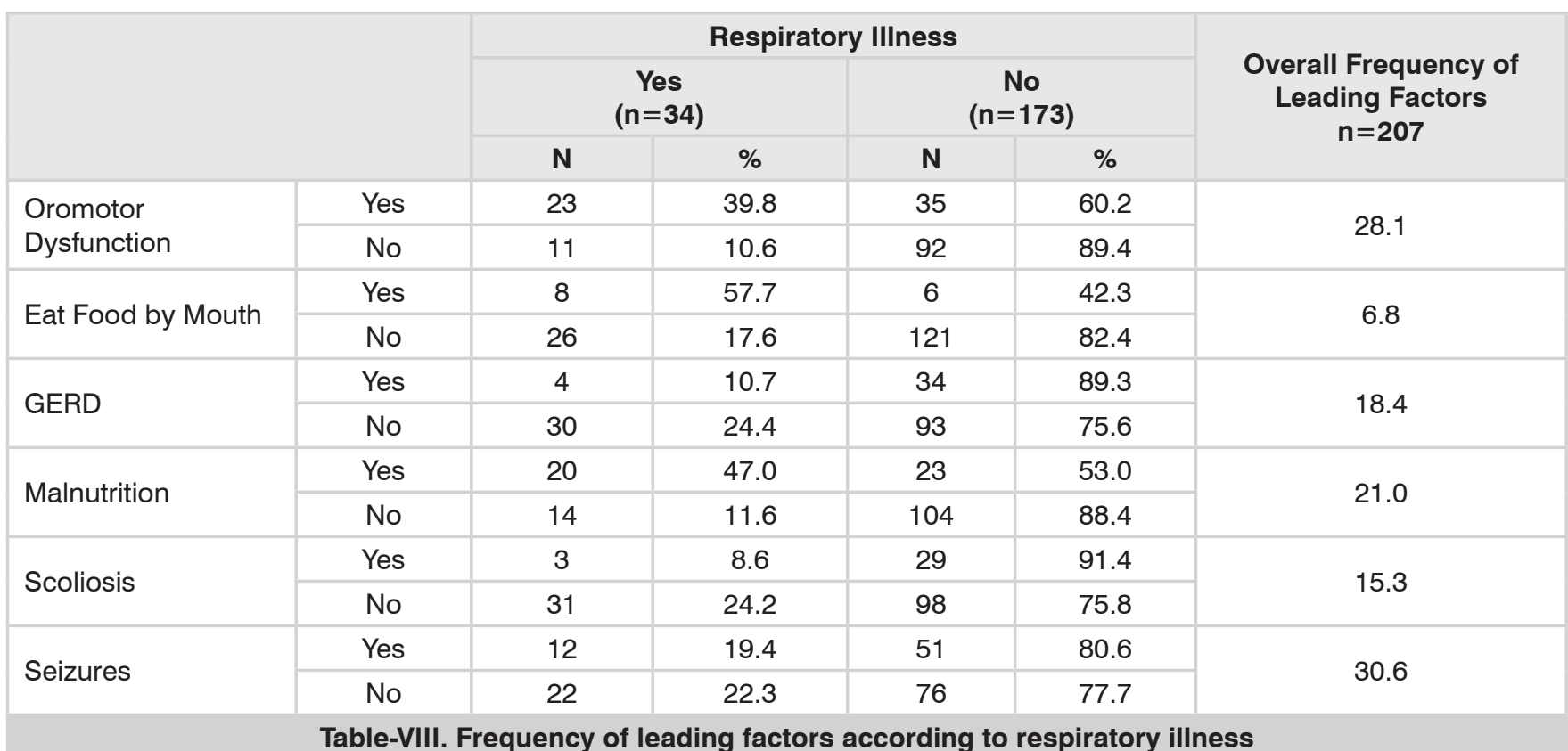

\section{DISCUSSION}

Our study demonstrate that respiratory illnesses contributes to frequent hospital admissions and many comorbid conditions have positive impact on frequency of Respiratory disease. The reasons for this population's vulnerability to respiratory disease are complex and not understood fully.

Our study shows that $16.8 \%$ of admissions were because of respiratory illnesses, as CP children are 5 to 7 times more prone to respiratory problems. Various potential risk factors have been suggested, including dysphagia leading to aspiration of saliva and/or nutritional intake, impaired motor function, absence of or a reduction in protective reflexes related to swallowing, and impairment in muscle strength and coordination pertaining in particular to the respiratory muscles.

It has been seen that $52 \%$ patients aged less than 7 years and among them 24\% have respiratory illnesses. Similar results regarding admission among this age group has been reported by Blackmore et al and N. L Young et al. Reason behind this age distribution may be tolerance developed in parents with time for these symptoms or they become trained enough to self-treat them at home. Education of parents, prophylaxis, early and rapid help at social and community level is the also reason behind this in developed countries.
But there is need to investigate each aspect of this trend among these age groups in our population. In a study on Australian population hospitalization due to respiratory illness is $47 \%$ in $0-4 y r s$, while $13 \%$ in age group 5-14years.

Pruitt et al states that along with physical disabilities, CP suffers from other systemic problems, together they have devastating effect on child health resulting in frequent hospital visits. Our study inquires few of these systemic issues. Among them seizures were reported in $19.4 \%$ of cases with respiratory illnesses. According to young et al epilepsy and pneumonia were among the five most common reasons for admission. Blackmore et al document that $22.6 \%$ of CP child have seizures disorder. Pruitt and Tsai states that $15-55 \%$ CP children and adults have seizures.

Oromotor dysfunction accounts for $39.8 \%$ of our study population. Blackmore et al reported that it contributes to chest infections, antibiotic use and frequent hospital admission in CP and $29.7 \%$ of their study population have oromotor dysfunction. Most of CP children with this dysfunction are silent aspirator.

GERD was found in $10.7 \%$ of CP child with respiratory illness, similar incidence is reported by Blackmore et al. Decreased oral muscle tone, 
uncoordinated pharyngeal muscle contractions and postural deformities along with GERD leads to aspiration of reflux. Sometime aspiration may mimics or presented with signs and symptoms of asthma and therefore less reported.

Scoliosis was found in $8.6 \%$ of inpatients. Scoliosis along with low upper to lower chest diameter and chronic lung diseases causes increase frequency of respiratory illnesses. Scoliosis causes reduced lung capacity and may make individuals more susceptible to respiratory illness. Hospital admissions for respiratory diseases are known to be higher in children with $\mathrm{CP}$ who have more severe gross motor impairments.

$57.7 \%$ admitted patients who eat by mouth have respiratory problems. Nasogastric or gastrostomy feeding often is considered in children with $\mathrm{CP}$ who have difficulty with swallowing, primarily to facilitate adequate nutrition. Results of one study showed that those who took all nutrition by nasogastric or gastrostomy tube (nil by mouth) were at the highest risk of respiratory hospitalizations and $50 \%$ of them reporting respiratory illnesses leading to hospital admissions in the previous 12 months. In this study $42.3 \%$ of admitted patients use different mode of food intake and $17.6 \%$ of patients with respiratory illnesses have mode of food intake other than oral. The children who received tube feedings are likely those with the most severe dysphagia. In particular, those children who receive all nutrition by tube are likely to have been instructed to avoid oral feeding because of a high risk of aspiration.

Our study results revealed that among total patients admitted with respiratory illness 47\% patients were malnourished, however overall malnutrition was observed in $21 \%$ of admitted cases. Malnutrition is common in this area of subcontinent. Chronic illnesses and disabilities and may be poor nursing care led to it. There are multiple reasons behind not providing adequate nutrition in quality and quantity, this further needs to investigate thoroughly.

There is dire need to design validated respiratory risk questionnaire. This will enable healthcare professionals to design preventive strategies and comprehensive care. These efforts will decrease diseases burden on both family and health department.

\section{CONCLUSION}

Cerebral palsy is an umbrella word which covers not only physical disabilities but also multiple concomitant systemic medical issues and disturbed mental health. This vulnerable group of CP children makes a good chunk of childhood disease burden in both inpatient and outdoor patient department but is most ignorant. This study covers specific aspect i.e. respiratory illness and leading factors, of their health issues. Multidisciplinary approach should always be provided to CP children at hospital as well as community level along with parent education related to disease problems. Objective of this study has been achieved and respiratory illnesses account for $16.8 \%$ among admitted cases of CP. Factors like mode of food intake, oromotor dysfunction and Malnutrition are significantly reported. These factors need to be addressed thoroughly. Preventive measurements and treatments should be individualized for leading factors.

\section{Copyright $@ 04$ Nov, 2019.}

\section{REFERENCES}

1. Accardo PJ, editor. Capute and Accardo's neurodevelopmental disabilities in infancy and childhood. Third ed: Paul H. Brookes Publishing Co; 2008.

2. Center of disease control and prevention, Data \& Statistics for Cerebral Palsy. 2017 [updated 2017; cited 2017 09/08/2017]; Available from: https://www. cdc.gov/ncbddd/cp/data.html.

3. Rosenbaum P, Paneth N, Leviton A, Goldstein M, Bax $M$. The definition and classification of cerebral palsy. Dev Med Child Neurol. 2007; 49(6):480.

4. DavidW. Pruitt Tt. Common medical comorbidities associated with cerebral palsy. Phys Med Rehabil Clin N Am 2009; 20 453-67.

5. Blackmore AM, Bear N, Blair E, Gibson N, Jalla C, Langdon K, et al. Factors associated with respiratory illnesses in children and young adults with cerebral palsy. The Journal of Pediatrics. 2016; 168:151-7. 
6. Young NL, McCormick AM, Gilbert T, Ayling-Campos A, Burke T, Fehlings D, et al. Reasons for hospital admissions among youth and young adults with cerebral palsy. Archives of Physical Medicine and Rehabiliation. 2011; 92:46-50.

7. Meehan E, Reid SM, Williams K, Freed GL, Sewell JR, Vidmar S, et al. Hospital admissions in children with cerebral palsy: A data linkage study. Developmental Medicine \& Child Neurology. 2017; 59:512-9.

8. A. Benfera K, A. Weirb K, L. Bella K, S. Warec R, S.W. Davies $P, N$. Boyda. R. Clinical signs suggestive of pharyngeal dysphagia in preschool children with cerebral palsy. Research in Developmental Disabilities. March 2015; 38:192-201.
9. El-Refaey BH, Maksoud GMA-E, Ali OI. Efficacy of feedback respiratory training on respiratory muscle strength and quality of life in children with spastic cerebral palsy: Randomized controlled trial. Bulletin of Faculty of Physical Therapy. 2017; 22:46-52.

10. Mirrett PL, Riski JE, Glascott J. Video fluoroscopic assessment of dysphagia in children with severe spastic cerebral palsy. Dysphagia 1994; 9: 174-9.

\begin{tabular}{|c|c|c|c|}
\hline \multicolumn{4}{|c|}{ AUTHORSHIP AND CONTRIBUTION DECLARATION } \\
\hline Sr. \# & Author(s) Full Name & Contribution to the paper & Author(s) Signature \\
\hline 1 & Dilshad Qureshi & $\begin{array}{l}\text { Supervised the study, helped } \\
\text { in interpreting the data and in } \\
\text { preparing the manuscript. }\end{array}$ & \\
\hline 2 & Shazia Bano & $\begin{array}{l}\text { Helped in designing the study, } \\
\text { interpreting the data and } \\
\text { finalizing the manuscript. }\end{array}$ & \\
\hline 3 & Hira Idrees & $\begin{array}{l}\text { Designed the study, interpreted } \\
\text { the data and prepared the } \\
\text { manuscript. }\end{array}$ & \\
\hline 4 & Saima Iram & $\begin{array}{l}\text { Helped in filling the performa } \\
\text { and finalizing the manuscript. }\end{array}$ & \\
\hline
\end{tabular}

